\title{
Implementation of Energy Harvesting System Using Soil for Agriculture Parameters Monitoring and Controlling using IOT
}

\author{
Dhanshree S. Kale ${ }^{1}$, Dinkar L. Bhombe ${ }^{2}$, Dhiraj P. Tulaskar ${ }^{3}$ \\ P.G. Student, Dept. of E and TC, SSGMCE, Shegaon, Maharashtra, India ${ }^{1}$ \\ Associate Professor, Dept. of E and TC, SSGMCE, Shegaon, Maharashtra, India ${ }^{2,3}$
}

\begin{abstract}
Rarely do we consider soil a battery or a wellspring of power. However, Energy is effectively harvesting energy from soil, residue and waste water and, with the utilization of imaginative power management hardware, is changing over earth into a valuable wellspring of clean dependable power. Harvesting energy in an open, uncontrolled environment postures challenges. This project utilizes the common metabolic pathways of microbes discovered pervasively in soil, residue, and wastewater. In these enviroments, microbes act as natural catalysts to exchange electrons outside their cell walls, in this manner creating a little electrical charge in the surrounding substrate. This charge, measured as a Reduction-Oxidation (RedOx) potential, is specifically gathered by the BES electrodes, creating electrical current. With present and potential, you have power. In an open framework, new nourishment items and natural waste items guarantee an unending supply of fuel for the BES, empowering industrious power era. The area of the BES electrodes in the dirt guarantees that the power framework is discrete and covered. This energy is created by soil is utilized as a part of field of ongoing checking of moisture of soil giving alarming system that is cautioning alert to farmer's telephone when certain condition happens in light of Wireless Farming System can effectively manage agricultural generation and enhance crop yield. The utilization remote sensor organize empowers sensation of parameter by utilizing microcontroller which acknowledges information from sensor and transmitted to the farmer through the IOT which give direct access to the web and get the data from the Agricultural area to the customer PC.
\end{abstract}

Keywords: Soil moisture sensor, Temperature sensor, Wireless sensor network, Microcontroller, IOT.

\section{INTRODUCTION}

Energy plays a vital part in our life. Fossil fuels are depleted and the demand for option energy production has an expanding pattern. Renewable energy might be a reasonable option for existing energy sources. Power generated from soil is considered as renewable energy. Soil give new chances to creation of bio-energy from organic and inorganic sources .The organic matters are changed over to hydrogenwithin the sight of dynamic biocatalysts in anode chamber under anaerobic condition. Microorganisms are utilized as a part of soil is to change over natural and inorganic compounds into bioelectricity. The idea of bioelectricity production was presented in recent decades.

The Paper comprises of wireless sensor networks nodes and system administration stage. The automatic networking acknowledges through the many jump routing utilization, adaptable programmed networking temperature humidity monitoring arrangement of soil. The framework is a total arrangement of wireless sensor network acceptance, storage capacity, application, revealing, arrangement, has a decent man PC trade interface.Users require not go into farmland, in a corner anywhere in the world, could prompt understand the changing state of farmland soil temperature and moisture and different elements, and logically manage agricultural generation. In this paper proposes to design, create and execute a wireless sensor network connected with a central node utilizing WIFI, which thusly was associated with a Central Monitoring Station (CMS) through General Packet Radio Service (GPRS) or Global System for Mobile (GSM) advancements. The framework likewise gets Global Positioning System (GPS) parameters identified with the field and sends them to a central monitoring station. This framework was relied upon to help famers in assessing soil conditions and act in like manner. To screen innovative poly house remote sensor created with microcontroller and WIFI for secure information transmission. Utilization of smart sensor module causes to improve the precision and reliability. This was survey distinctive monitoring frameworks and proposed a programmed checking framework display utilizing Wireless Sensor Network (WSN) which helps the Farmer to enhance the yield. This review plans to give observing of environment and give favourable advantage of simple arrangement, in real time monitoring. [1]

To expand the efficiency of the farms one needs to utilize ideal water for this water system framework is use to enhance water administration and for the controlling their parameter of farm remote sensor system is depicted which store and used rain water to build their crop productivity, to reduce the cost for development and make utilization of real time 


\section{ISO 3297:2007 Certified}

Vol. 5, Issue 4, April 2017

values. In this paper different farming parameters are monitor and control by utilizing peripheral gadgets likevalve, watering pump and so forth and screen consequently utilizing microcontroller to enhance the farmer yield. This framework is utilized for enhancing water assets for farming creation, the places with water shortage.

\section{III.HARDWARE DESIGN}

\section{A. Transmitter section}

Probes: A designed resistive sensor is used to sense the moisture content in the soil. It works on the principal of electrical conductivity. Resistance of the sensor is inversely proportional to moisture content in the soil.Moisture content of the soil is a major factor determining plant growth. The present work Comprises of development of a soil moisture sensor.Figure 1 shows the Photograph of a Soil Moisture Sensor.

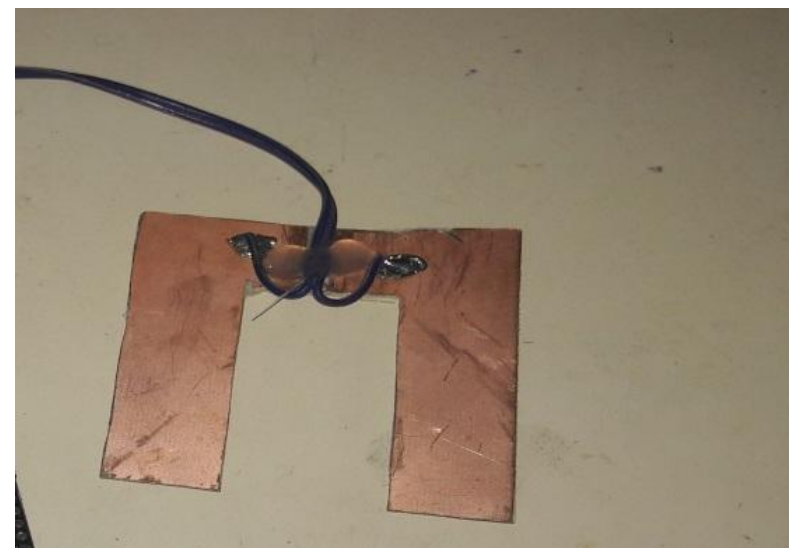

Fig. 1: Photograph of a Soil Moisture Sensor

The soil moisture sensor have been developed using the basic property that the resistance of the soil between two points decreases with the increase of water content in it. We know that water is a good conductor of electricity in the presence of ions. So, greater the amount of electrolytes in the soil, greater will be the conductivity of the soil. This means that the resistance of the soil decreases. The basic objective of irrigation scheduling is to minimize water stress of the plant, that of over irrigation and under irrigation. Good irrigation water management will increase yields, improve crop quality, conserve water, save energy and decrease fertilizer requirements. The probes are made using two metal rods tied together using a block. The two probes are separated using smaller foam block which keeps the two probes apart. The developed sensor has two probes that are inserted into the soil. The distance between these two probes is kept fixed. A resistance between two probes is kept fixed.A Resistance is connected in series with the probe and current passed through it.

\section{Signal Conditioning Circuit for Esp8266 Wifi Module}

The circuit consist ofcopper and zinc plate for creating energy. When you place a copper plate (electrode) and a zinc plate (electrode) in a container of mud (it has to be wet), the two metals start reacting, because zinc tends to lose electrons more easily then copper and because dirt contains ions. In which copper plate goes about as an Anode and zinc plate goes about as a Cathode. Wetting the dirt turns it into a true electrolyte "solution." So the electrodes start exchanging electrons, just like in a standard battery. In this way it makes energy from soil. We used 8 plates for energy Harvesting. Since blend one zinc and one copper plate makes energy up to $1.1 \mathrm{~V}$, so we utilized four mixes of zinc and copper plate serially. In this way it energizes to $4 \mathrm{~V}$. This setup gives theDC values depending on the resistance due to soilbetween the probes. The output of the sensor ischange in resistance as per the moisture contents inthe soil. The change of resistance is from $1 \mathrm{~K}$ to $15 \mathrm{Kdepending}$ upon moisture. This change in resistanceis required to be converted into correspondingvoltage change and for this purpose signalconditioning circuit is used. The signal conditioningcard gives a voltage change from $4 \mathrm{~V}$ to $0 \mathrm{~V}$ which iscompatible with further circuitry. Theelectrodes measure the resistance to electric currentwhen electrical energy is applied. The Overview of Transmitter Circuit is shown inFigure 2. The ESP 8266 WIFI Module (TX) takes the analog sensor values and converts them into a digital value using Analog to Digital Converter (ADC).ESP 8266 consist of one ADC channel of 10bit resolution which converts analog moisture value to its digital form and send to ESP 8266 WIFI Module (RX) or android mobile app, which send data to Server .The output of the sensor is depends on ESP 8266 WIFI Module. When the sensor is dry ( $0 \%$ moisture), theresistance of the sensor is around $15 \mathrm{~K}$, the $\mathrm{ADC}$ is set to $4 \mathrm{~V}$ for $0 \%$ moisture. As the moisture increases, resistance of theblock decreases. The voltages of the ADC are set to $0 \mathrm{~V}$ for $100 \%$ moisture. 


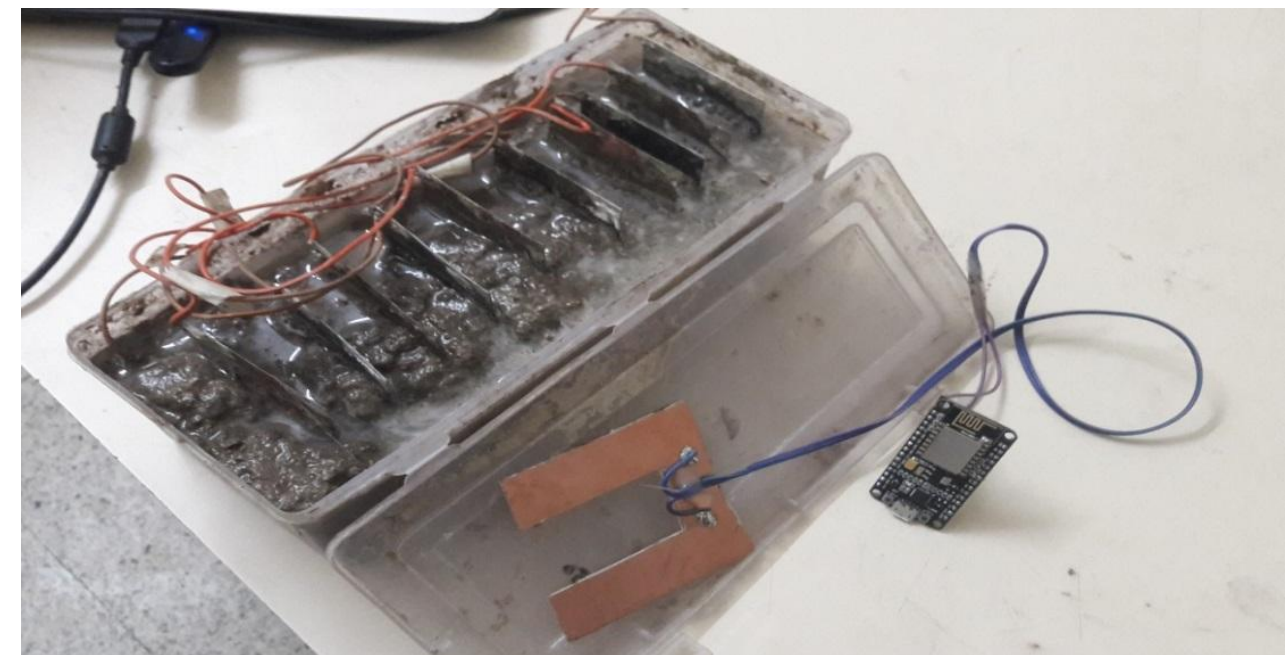

Fig.2: Overview of Transmitter Circuit

\section{B. Receiver section}

\section{Microcontroller atmega 2560}

Here the basic task is to automate the irrigation process. For this here is the need to have information about the present water content in the soil. This information is gathered using soil moisture sensors and ESP 8266 WIFI module (TX).The moisture sensor that is made here gives an analog voltage value ranging from 0 to $4 \mathrm{~V}$ for different moisture levels. The Arduino has a program running on it, which acts as a small operating System. It has a user interface, and takes inputs from the user and accordingly takes actions. If the digital value calculated for a sensor is less than its reference value. It means that there is less soil moisture present than the required in that area. Microcontroller must turn on water supply for that area. This is achieved by turning on a relay, which in turn opens a water valve, and water is given to only that area of the field. Atmega 2560 is used as controller for the system in field station. It reads the actual data from the ADC and compares it with the values of witting points, which are already, stored in it, for different crops. Depending upon this comparison it makes decision whether to initiate irrigation or not. And also it sends the Current data to web server for data acquisition. This transmission of data from field to web server is done through ESP 8266 WIFI Module it is used to control the overall action. Pin no. 8 to 13 is used to connect the LCD Display for displaying purpose and the Port D.0 is used to connect ESP 8266 WIFI Module for receiving the data coming from field to the web server. Relay is connected to pin 4 of arduino for turning ON and OFF pump.

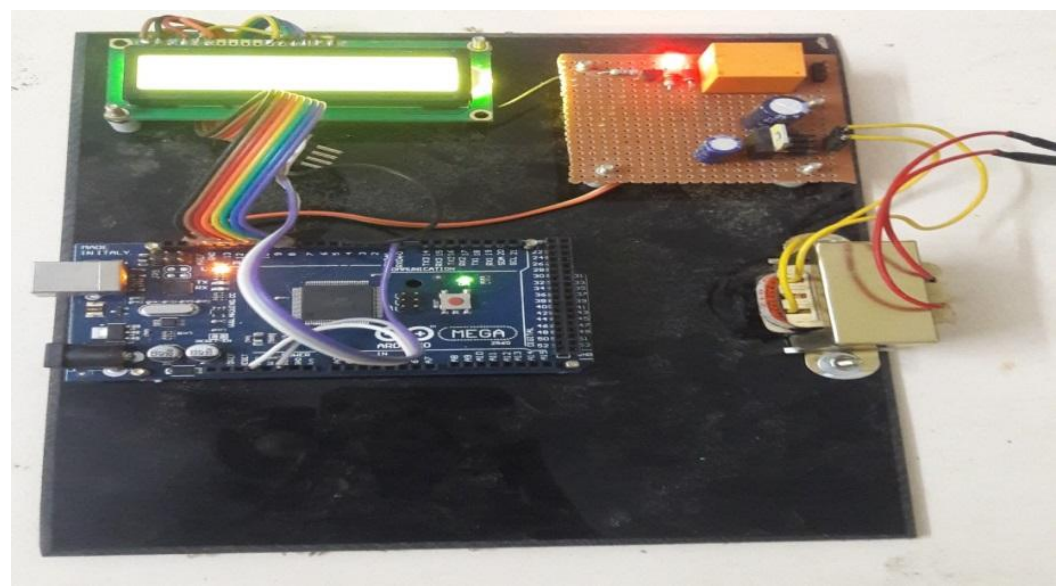

Fig. 3: Overview of a Receiver Circuit

The Figure3. shows Overview of Receiver.The ESP module supports standard IEEE802.11 b/g/n agreement, complete TCP/IP protocol stack. Users can use the add modules to an existing device networking, or building a separate network controller.ESP8266 is high integration wireless SOCs, designed for space and power constrained mobile platform designers. It provides unsurpassed ability to embed $\mathrm{Wi}-\mathrm{Fi}$ capabilities within other systems, or to function as a standalone application, with the lowest cost, and minimal space requirement. 


\section{SOFTWARE DESIGN}

\section{A. Software at Field Station}

As ESP 8266 WIFI module is compatible with microcontroller; the control action is taken in the field station only by microcontroller, in which the set points of the present conditions are given.
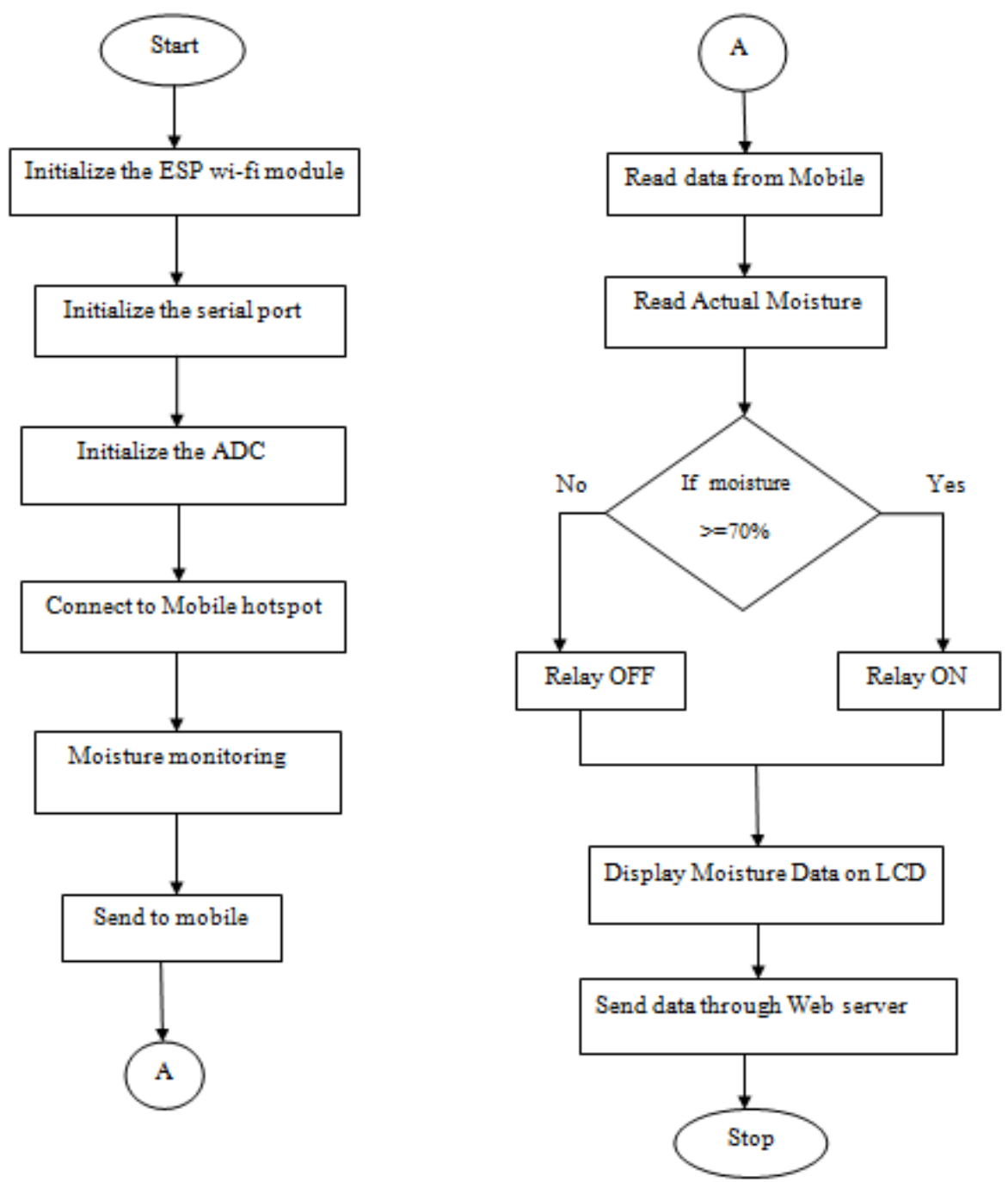

Fig.4: Transmitter Flowchart

In this if the data coming from field is less than $70 \%$ then the irrigation is start and the display shows thepresent moisture contents and the "Motor ON ". If the moisture contents in the soil are 80 above $70 \%$ then the irrigation is OFF and display shows "Motor OFF" on the screen. In the decision routine current soil moisture of signal is continuously compared with selected set points. If this signed is less than wilting point valve get open or valve gets closed when signal is greater than maximum set point.

\section{B. Software at Central Station}

As ESP 8266 WIFI Module (TX) is compatible to microcontroller, the data is received by the ESP 8266 WIFI Module $(\mathrm{RX})$ and then this data is display on LCD using Atmega 2560 Microcontroller.

We utilize arduino IDE software.Arduino is an open-source extend, empowering specialists to effortlessly exploit the effective Atmega chips. The Arduino IDE is the product where you can compose code and transfer it to the Atmega chip. The code is then executed on the chip. ESP 8266 WIFI Module sends information to server through amazon web administrations. AWS makes URL and sends information to cloud administrations. The made URL sends information on cloud benefit. When we get to the produced URL then, web attachment is made .Through this web attachment we can make log document. This log record can be downloaded through URL. The made URL keeps the information of 
soil parameter which can be gotten to from anyplace. The uploaded data on cloud through IOT can be accessed through internet anywhere in the world.

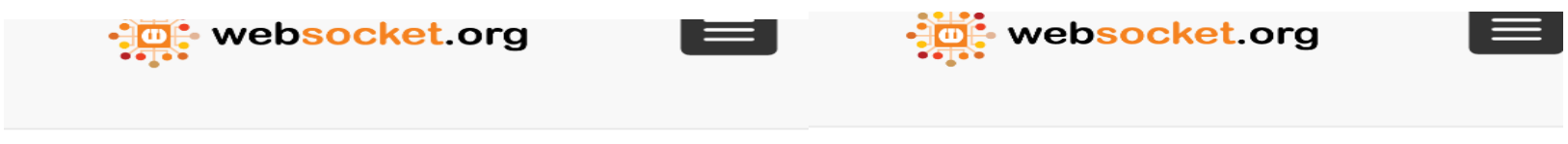

Try it out!

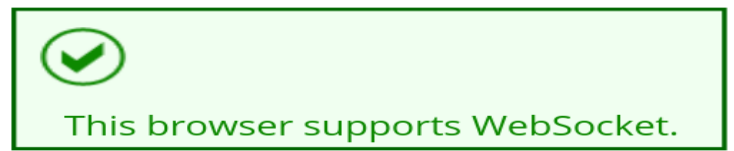

Location:
WS://52.37.105.1:8886/ws
$\square$ Use secure WebSocket (TLS)
Connect Disconnect

Message:

Rock it with HTML5 WebSocket

Send

Log:

RESPONSE: $\sim$ !

RESPONSE: $\sim$ O!

RESPONSE: $\sim \mathrm{O}$ !

RESPONSE: $\sim \mathrm{O}$ !

RESPONSE: $\sim 0$ !

Clear Log

Download Log
Try it out!

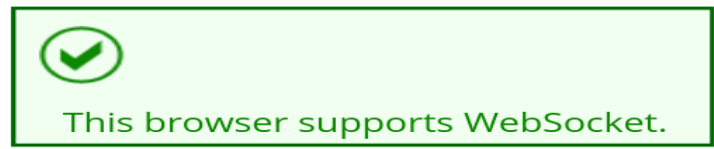

Location:

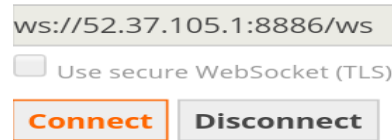

Message:

Rock it with HTML5 WebSocket

send

Log:

RESPONSE: $\sim 100$ !

RESPONSE: $\sim 100$ !

RESPONSE: $\sim 100$ !

RESPONSE: 100!

RESPONSE: $\sim 100$ !

Clear Log

Download Log
Note: In some environments the WebSocket connection may fail due to intermediary firewalls, proxies, routers, etc. In that case take advantage of WebSocket's secure capability and check Use secure Websocket (TLS). Even if you have no issues you can still feel free to test

Fig.5: Captured image of moisture at $0 \%$
Note: In some environments the WebSocket connectior may fail due to intermediary firewalls, proxies, routers, etc. In that case take advantage of WebSocket's secure capability and check Use secure Websocket (TLS). Even if you have no issues you can still feel free to test using a secure connection.

Fig.6: Captured image of moisture at $\mathbf{1 0 0 \%}$

\section{RESULT}

In drip irrigation control system hardware and software is designed for uniform application of water directly to the plant root zone to maintain soil moisture within the range for good plant growth without excessive water loss, erosion, reduction in water quality, or salt accumulation. Controller continuously acquires data from ESP 8266 WIFI Module .Soil moisture sensor senses the soil moisture and accordingly solenoid valve gets open or close when needed. The controllers proved to be effective in maintaining the soil water content in the plant as per the set points of the plant. The drip irrigation system has been satisfactorily tested under ideal conditions of controlled irrigation of plant to maintain soil moisture in the range of a model-based system. The system is working fine and the water requirement of the soil is kept well above the wilting point. When the soil moisture drops the minimum value then irrigation starts and the soil moisture is continuously sense and displayed on the LCD. The moisture sensor being developed give an analog value ranging from $5 \mathrm{~V}$ to $0 \mathrm{~V}$ for different moisture levels. For soil moisture sensor a special sensor is developed which has variable resistance with respect to variation in soil moisture. 


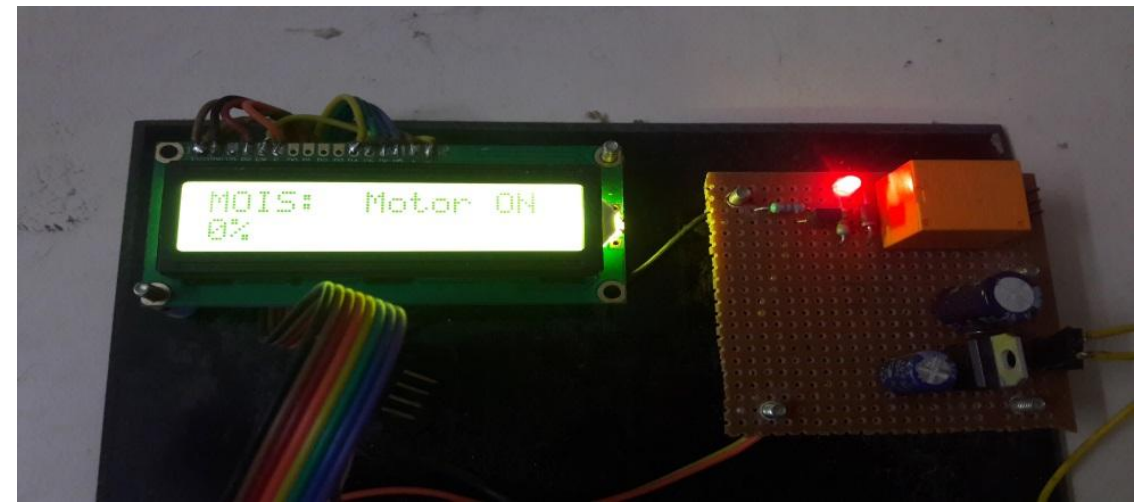

Fig.7: Moisture at 0\%

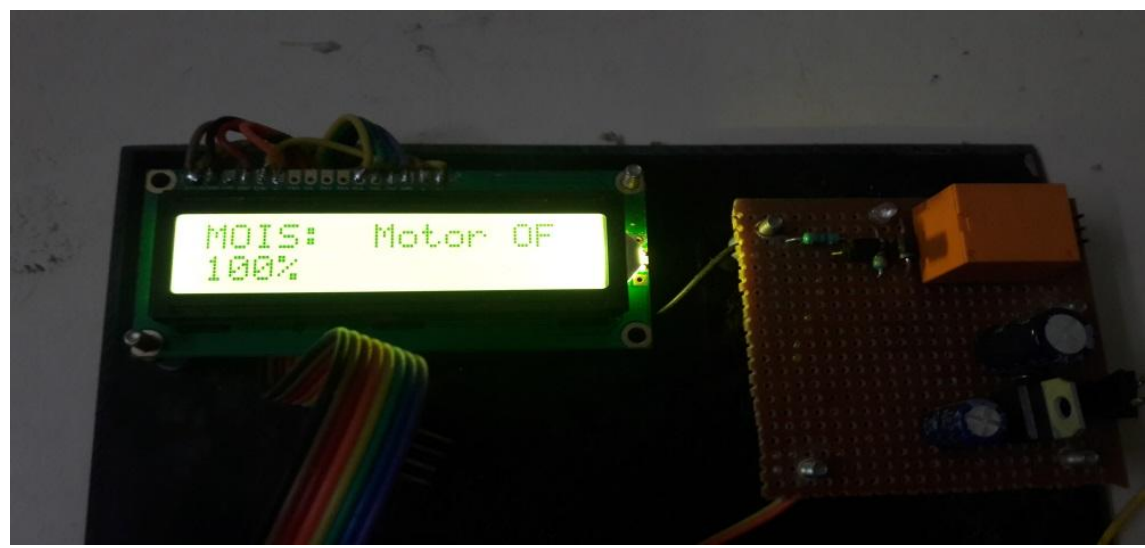

Fig.8: Moisture at $100 \%$

\section{VI.CONCLUSION}

Implementation of Wireless Sensor Network For Real Time Monitoring of Agriculture Parameter used to increase the yield of plants by monitoring and controlling environmental conditions (parameter) and thus providing necessary information to the farmers. The use wireless sensor network enables sensation of parameter by using microcontroller which accepts data from sensor and transmitted to the farmer through the IOT which provide direct access to the internet and get the information from the Agricultural area to the client PC. It also can provide scientific basis for highprecision monitoring and calculating for farmland drought and flood area. Against the background of global information and digitization, traditional agriculture is gradually turning into digital agriculture.

\section{REFERENCES}

1. Samuel Raj, Jebakumar Solomon, Prathipa , Anis Kumar,"Production Of Electricity From Agricultural Soil And Dye Industrial Effluent Soil Using Microbial Fuel Cell," IJRET: International Journal of Research in Engineering and Technology eISSN: 2319-1163 |pISSN: $2321-7308$.

2. Julakanti Preetham Kumar, Dr Syed Umar, Chunduri Sree Harsha Bommareddy Nagasai, "Implementing Intelligent Monitoring Techniques in Agriculture Using Wireless Sensor Networks," Julakanti Preetham Kumar et al, / (IJCSIT) International Journal of Computer Science and Information Technologies, Vol. 5 (4) , 2014, 5797-5800.

3. Joaquín Gutiérrez, Juan Francisco Villa-Medina, Alejandra Nieto-Garibay, And Miguel Ángel Porta-Gándara “Automated Irrigation System Using A Wireless Sensor Network And Gprs Module,” IEEE Transactions On Instrumentation And Measurement, Vol. 63, No. 1, January 2014.

4. Qiang Wang, Andreas Terzis, Alex Szalay, “A Novel Soil Measuring Wireless Sensor Network,” 978-1-4244-2833-5/10/\$25.00 @2010 IEEE.

5. Renuka Arbat, "Implementation of Wireless Sensor Network for Automatic Irrigation by Using GPRS," International Journal of Innovative Research in Computer and Communication Engineering (An ISO 3297: 2007 Certified Organization) Vol. 4, Issue 3, March 2016.

6. Nikesh Gondchawar, Prof. Dr. R. S. Kawitkar, “ Iot Based Smart Agriculture,” International Journal Of Advanced Research In Computer And Communication Engineering Vol. 5, Issue 6, June 2016.

7. G. Merlin Suba, Y M Jagadeesh, S Karthik And E Raj Sampath, "Smart Irrigation System Through Wireless Sensor Networks," ARPN Journal Of Engineering And Applied Sciences, Vol. 10, No. 17, September 2015.Vol. 10, No. 17, September 2015.

8. SulakheVinayak V,Dr. Mrs. S.D.Apte, "Real Time Monitoring Of Agri-Parameters Using Wsn For Precision Agriculture," International Journal Of Advanced Research In Computer Science And Software Engineering,Volume 3, Issue 9, September 2013.

9. Hemavathi G, Sudha V, "WSN Based Parameters Monitoring And Control For Specialized Mining Equipment," International Journal Of Advanced Research In Electrical,Electronics And Instrumentation Engineering, Vol. 4, Issue 4, April 2015. 
10. Dhanshree S. Kale ${ }^{1}$, Dinkar L. Bhombe ${ }^{2}$, Dhiraj P. Tulaskar,” Implementation of Soil Energy Harvesting System for Agriculture Parameters Monitoring and Controlling Using IOT: A Review” International Research Journal of Engineering and Technology(IRJET) ,Volume: 03 Issue: $10 \mid$ Jan -2017

11. https://www.google.co.in/?gfe_rd=cr\&ei=nILvWMWaHuvx8AfkloHQCw

12. http://www.academia.edu/15565566/Determination_of_soil_moisture_using_wavelet_analysis

\section{BIOGRAPHIES}

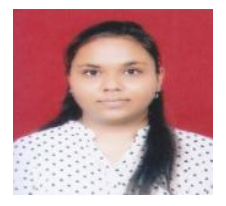

Dhanshree S. Kale is Student of Master of Engineering (Digital Electronics) of Shri Sant Gajanan Maharaj College of Engineering, Shegaon. Received her B.E. degree from P.R. Patil C.O.E.T, Amravati. Her areas of interests is, Embedded systems, power Electronics.

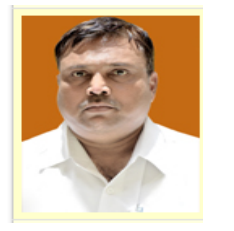

Dinkar L. Bhombe received the MS degree in Electronics and Control Engineering from the BITS Pilani, India and doing PhD degree in Electronics engineering from SGB Amravati University Amravati, India. He is currently an Associate Professor at the SSGM College of Engineering Shegaon India. His research interests include Neuro Fuzzy application to Image and Signal Processing.

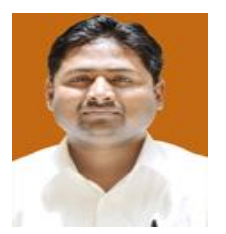

Dhiraj P. Tulaskar received the Master degree in DigitalElectronics Engineering from Shri Sant Gajanan Maharaj College of Engineering, Shegaon., India and doing PhD degree in Electronics engineering from SGB Amravati University Amravati, India. He is currently a Assistant Professor at the SSGM College of Engineering Shegaon India.His research interests include RF Microwave and circuit Design. 